\title{
Inverted Meckel's diverticulum presenting as iron deficiency anemia
}

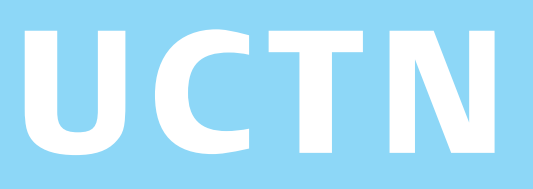

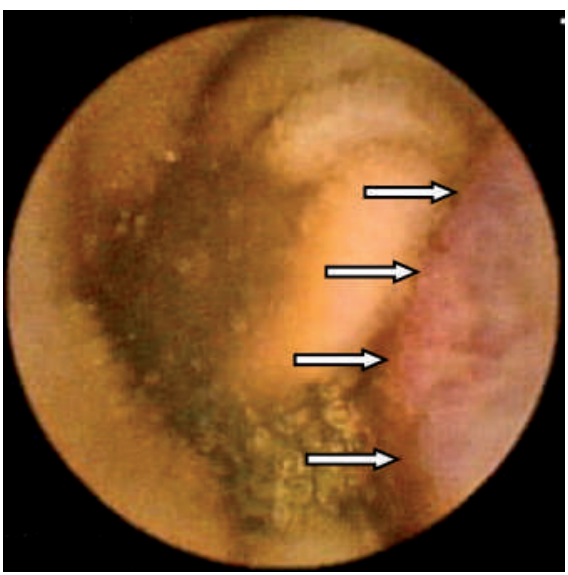

Figure 1 Video capsule endoscopy revealed a pink-colored, bulging mass (arrows) in the ileum, which we suspected to be a tumor.

A 48-year-old woman presented with fatigue, dyspnea on exertion, and mild abdominal bloating. Physical examination was unremarkable, with a soft nontender abdomen. Laboratory evaluation revealed iron deficiency anemia, with a hemoglobin level of $10.2 \mathrm{~g} / \mathrm{dl}$ (normal range 12$16 \mathrm{~g} / \mathrm{dl}$ ) and a plasma ferritin of $8 \mathrm{ng} / \mathrm{ml}$ (normal range $10-291 \mathrm{ng} / \mathrm{ml}$ ). As part of the investigative work-up for her anemia, colonoscopy and esophagogastroduodenoscopy with duodenal biopsies were performed and no abnormalities were found. Capsule endoscopy revealed an intraluminal mass in the distal ileum, which we suspected to be a tumor (Video 1, Figure 1). Computed tomography was performed to further define the ileal mass, and the scan confirmed the presence of an endoluminal mass in the distal ileum (Figure 2).

An exploratory laparotomy was performed because of the patient's symptomatic anemia and the suspected smallbowel neoplasm. A $5-\mathrm{cm}$ intraluminal

\section{Video 1}

Video capsule endoscopy demonstrated a pink-colored mass protruding into the ileal lumen. The mass can be seen in the upper right-hand corner of the screen.
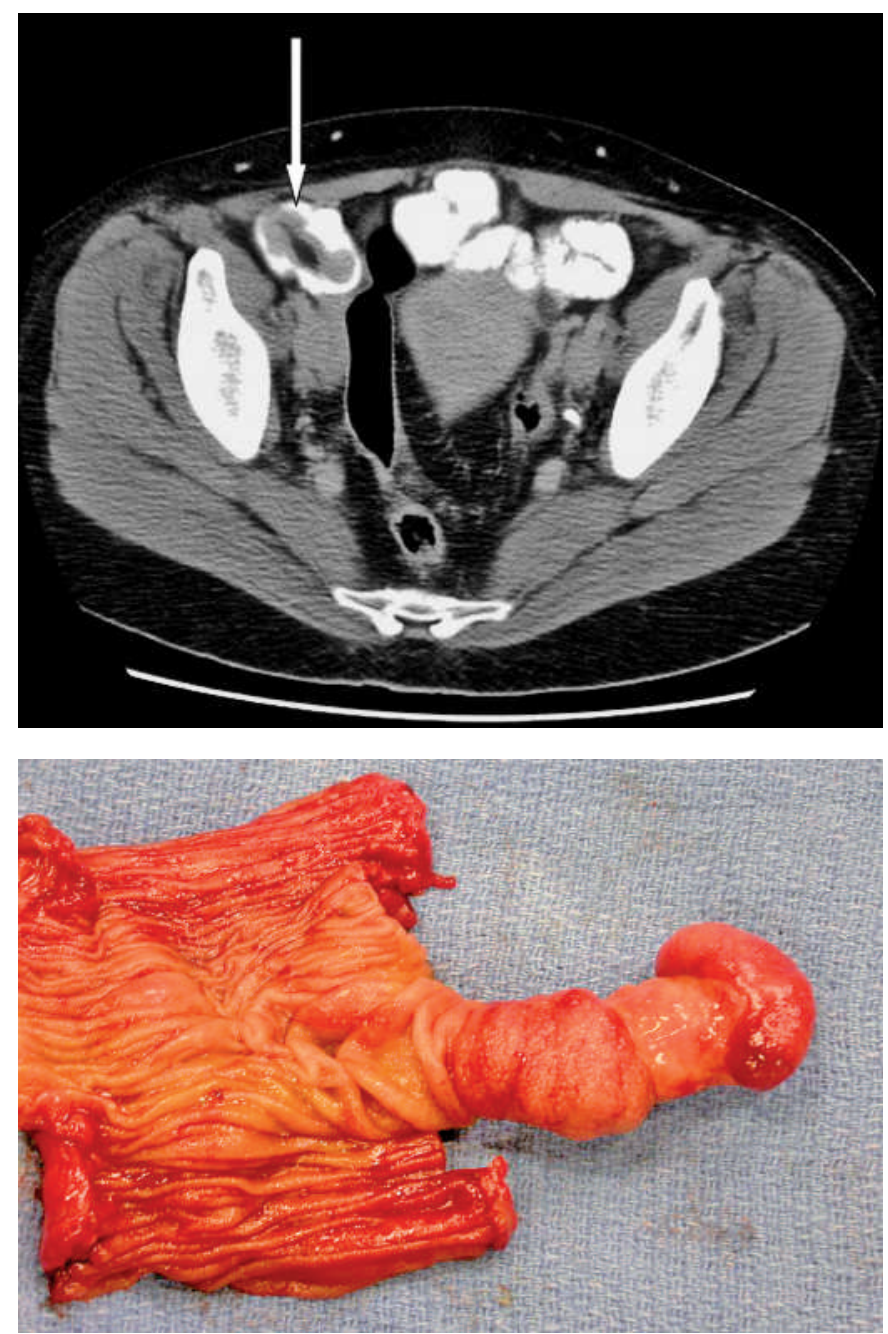

Figure 3 A short ileal segment was resected and was found to contain an inverted Meckel's diverticulum measuring $5 \mathrm{~cm}$ in length.

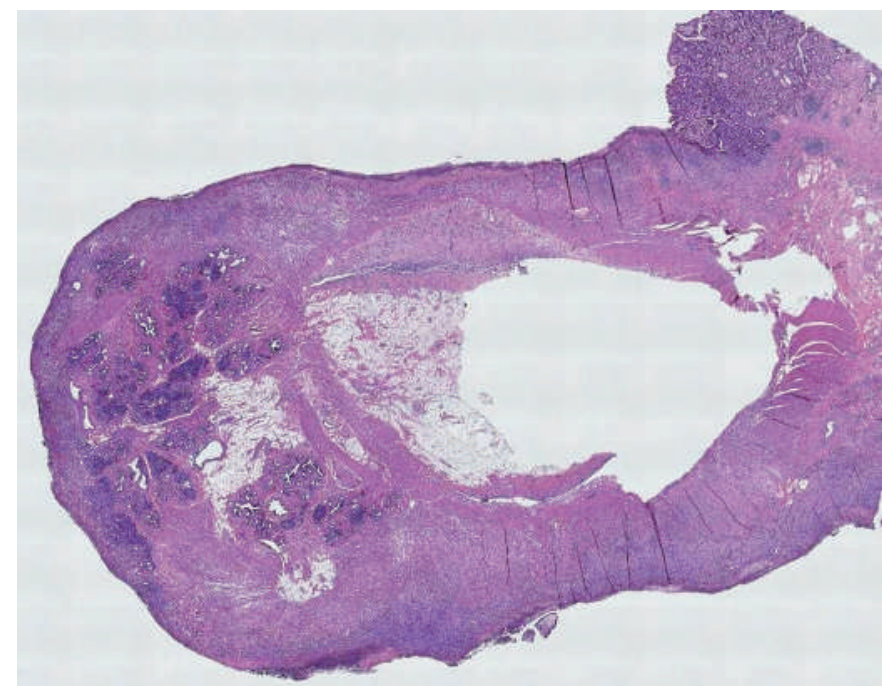

Figure 4 Pathological investigation revealed extensive surface ulceration and heterotopic pancreatic tissue, findings consistent with a Meckel's diverticulum (hematoxyin \& eosin, original magnification $\times 2)$. 
mass was palpated in the distal ileum. A point of invagination was seen on the antimesenteric border of the mass, consistent with an inverted Meckel's diverticulum. A short segment of bowel was resected (Figure 3). Histopathological examination of the specimen showed ulceration and heterotopic pancreatic tissue (Figure 4). The patient's anemia and symptoms resolved after the resection procedure.

Meckel's diverticulum usually presents with bleeding, obstruction, or diverticulitis [1]. This patient, on the other hand, presented with iron deficiency anemia, without any visible bleeding or significant gastrointestinal symptoms. Iron deficiency seems to be a most unusual presentation of Meckel's diverticulum [2]. This case illustrates this rare clinical presentation, highlighting the utility of video capsule endoscopy in the evaluation of anemia. Another unusual aspect of this case was the tumor-like appearance of the inverted Meckel's diverticulum on capsule endoscopy. The increasing use of video capsule endoscopy will probably lead to more frequent diagnosis of Meckel's diverticulum.
Endoscopy_UCTN_Code_CCL_1AC_2AF

\section{J. H. Shelton', T. W. Newsome'2, K. L. Ford III' ${ }^{3}$ J. K. Hamilton ${ }^{1}$}

${ }^{1}$ Department of Gastroenterology, Baylor University Medical Center, Dallas, Texas, USA

${ }^{2}$ Department of Surgery, Baylor University Medical Center, Dallas, Texas, USA

${ }^{3}$ Department of Radiology, Baylor University Medical Center, Dallas, Texas, USA.

\section{References}

${ }^{1}$ Park JJ, Wolff BG, Tollefson MK et al. Meckel diverticulum: the Mayo Clinic experience with 1476 patients (1950-2002). Ann Surg 2005; 241: 529-533

2 Puligandla PS, Becker L, Driman D et al. Inverted Meckel's diverticulum presenting as chronic anemia: case report and literature review. Can J Surg 2001; 44: 458-459

\section{Corresponding Author}

\section{J. H. Shelton, M.D.}

Department of Gastroenterology Baylor University Medical Center 3500 Gaston Avenue

Dallas

Texas 75246

USA

Fax: $\quad+1-214-818-8179$

E-mail: JHShelton1@yahoo.com 